REVISTA CHILENA DE LITERATURA

Noviembre 2009, Número 75, 171 - 197

\title{
INTERTEXTUALIDAD EN "VOCALES PARA HILDA" DE GONZALO ROJAS. UN DIÁLOGO ABIERTO CON RIMBAUD Y CÉSAR VALLEJO ${ }^{1}$
}

\author{
Héctor Véliz Gatica \\ Universidad de La Serena \\ aleph1899@hotmail.com
}

RESUMEN / ABSTRACT

El presente trabajo se propone demostrar la existencia de una intertextualidad entre el poema "Vocales para Hilda" de Gonzalo Rojas y los sonetos "Vocales" ("Voyelles") y "El dolor de las cinco vocales" de Arthur Rimbaud y César Vallejo, respectivamente. Para ello, se procedió con la recolección bibliográfica y revisión crítica de textos, además de un registro de los datos intratextuales (nivel fónico, gramatical y semántico) presentes en el poema. Los resultados obtenidos demuestran la existencia de dicha relación intertextual, por lo que concluimos que el texto de Rojas no se reduce a un poema de corte privativamente amoroso, ya que al plantearse en diálogo con los autores aquí considerados, se amplía y enriquece en su potencial de sentidos.

Palabras clave: intertextualidad, vocales para Hilda, Gonzalo Rojas, César Vallejo, Rimbaud.

The present work proposes to demonstrate the existence of an intertextuality between the poem "Vocales para Hilda" of Gonzalo Rojas and the sonnets "Voyelles" and "El dolor de las cinco vocales" of Arthur Rimbaud and César Vallejo respectively. To achieve this purpose a bibliographic recollection and a critical review of the texts has been done, and a register

1 Esta investigación fue financiada por el Proyecto DIULS PF/07201 de la Dirección de Investigación de la Universidad de La Serena. 
of the intertextual data present in the poem (phonic, grammatical, and semantic level) was also establihed. The results demostrated the presence of the above mentioned intertextual relationship, that is why it may be assumed that Gonzalo Rojas' text is not only a love poem; it also establishes a dialogue with the already mentioned Rimbaud and Vallejo, which means this poem has a much wider potential meaning.

KEY WORDS: Intertextuality, Vocales para Hilda, Gonzalo Rojas, César Vallejo, Rimbaud.

\section{INTRODUCCIÓN}

A pesar de los numerosos estudios existentes sobre la obra de Gonzalo Rojas y de la reconocida influencia que los autores A. Rimbaud y César Vallejo han ejercido en la poesía del autor chileno, no se han realizado estudios suficientes que analicen, en textos específicos del escritor, la forma en que los poemas de Rojas dialogan con los de dichos autores. De acuerdo con esto, hemos advertido en "Vocales para Hilda" , poema considerado siempre en la vertiente amorosa de su poesía, una oportunidad concreta para examinar dicha posibilidad.

"Vocales para Hilda" es un poema que forma parte de Oscuro, libro que aparece por primera vez en Caracas, en el año 1977. Es un poema que se ha ubicado en aquella vertiente de su poesía vinculada al amor o a una muy particular visión del erotismo. Forma en el libro, parte de la sección agrupada bajo el título ¿Qué se ama cuando se ama? Se trata de un poema de carácter laudatorio, extenso, de versos breves y agrupados en quince estrofas ${ }^{3}$, distribuidos de tal forma que su estructura deviene en una linealidad vertical ${ }^{4}$.

2 Todas las referencias a este poema serán extraídas de Antología de Aire (99-102). Por lo mismo, no creemos necesario indicar su procedencia en cada uno de los ejemplos que utilicemos. Si la cita corresponde a otro poema del autor, esto será debidamente señalado. Por otra parte, para facilitar la lectura de este artículo, hemos incluido en el apéndice, los tres poemas que han sido considerado para efectos del análisis.

3 Hemos partido de una arbitrariedad. Si bien los pronombres que aparecen individualizados, por su disposición visual pueden considerarse estrofas del poema, creemos más certero contar como estrofas los compartimientos que agrupan mayor cantidad de versos, considerando el tú reiterado como elemento divisorio antes que estrófico.

${ }^{4}$ Sin duda es importante manejar algunos datos extratextuales que pueden revelar un sentido autobiográfico en el poema. En este sentido, Hilda R. May es una referencia que debemos considerar, aunque preferimos mantenerlo como acápite, apostillas para un trabajo de pretensiones más críticas. "l' ostinato rigore". 
La lectura del poema nos ha permitido plantear la siguiente pregunta de investigación: ¿Existe una relación intertextual entre el poema "Vocales para Hilda" de Gonzalo Rojas y los poemas "Vocales" 5 y "El dolor de las cinco vocales" de A. Rimbaud y César Vallejo, respectivamente?

Demostrar la existencia de dicha intertextualidad es el objetivo del presente artículo. Con este propósito, hemos recurrido a una revisión bibliográfica crítica, la que incluye una lectura detenida de la obra de Rojas y una revisión rigurosa de artículos de investigación en torno a su obra. Por otro lado, realizamos un registro de los datos obtenidos al observar y describir los aspectos intratextuales del poema, a saber, los aspectos fónicos, gramaticales y semánticos. Los detalles de este procedimiento serán explicados debidamente.

Comprendemos que la mera detección de una relación entre los poemas no justifica la necesidad de una investigación al respecto, por lo que la discusión en torno a los resultados obtenidos se centra, principalmente, en determinar de qué forma esta se concretiza y cuáles serían sus posibles alcances e interpretaciones. Entendemos también, que es todo esto, en su conjunto, lo que involucra la realización de una legítima crítica de intertextualidad.

\section{MARCO TEÓRICO}

\section{CONCEPTO DE INTERTEXTUALIDAD}

Al decir de Grínor Rojo, la crítica debe pronunciarse a favor "no solo de la conveniencia, sino de la inevitabilidad de una crítica intertextual" (73). Esta idea se comprende desde el momento en que advertimos que el texto, objeto de análisis, no solo se amplía, sino que se enriquece en su potencialidad de interpretaciones. Por otro lado, dicha inevitabilidad se explica desde que asumimos que un texto o discurso no existe con independencia de otros, ya sean precedentes, sincrónicos o ulteriores a él.

5 Todas las referencias a este poema provienen de A. Rimbaud, Poesías Completas.

6 Este poema se encuentra en Obra poética (1988) de César Vallejo. Se trata de una edición crítica a cargo de Américo Ferrari. El poema es posterior a Los Heraldos Negros $\mathrm{y}$ anterior a Trilce, que en esta edición se recoge como "Poemas marginales a los heraldos negros" (155-157). 
Cuando hablamos de intertextualidad, nos estamos refiriendo a un entrecruzamiento o a una relación dialógica que se establece entre distintos discursos. Esto nos permite comprender que la crítica intertextual es la puesta en práctica de una teoría que resguarda la convicción de que "el texto no es la celda de clausura que hizo de él la superstición autonomista" (Rojo 88). $\mathrm{Al}$ aceptar que un discurso no existe en forma aislada, pues este es discurso en tanto se relaciona recíprocamente con otros, la pretérita concepción del texto como una unidad cerrada queda definitivamente en el olvido.

Una inquietud frecuente al momento de profundizar en la teoría de la intertextualidad guarda relación con el rol del lector en el proceso de decodificación de los intertextos; ¿qué sucede con la lectura e interpretación de un discurso cuando el lector no posee la suficiente competencia intertextual? ¿Dicho discurso se limita, necesariamente, en su potencial de sentidos?

Puede señalarse, al respecto, que la concretización de aquel dialogismo ha de manifestarse a través de distintos procedimientos o estrategias textuales; la cita, la alusión, la imitación o la transformación temática, entre otras. Por esto mismo, el papel del lector, en lo que a los mecanismos de producción de sentido respecta, se torna fundamental para establecer los alcances intertextuales de un discurso. En parte, el potencial de sentidos de estos se actualiza a partir de la enciclopedia o competencia cultural que posea un determinado lector. Ello, en cuanto la actividad interpretativa se postula como el mecanismo a través del cual el lector llena aquellos espacios en blanco presentes en el texto, aquellos intersticios que hacen del discurso una obra abierta, en el sentido propuesto por Umberto Eco. Aun así, debemos señalar que la recepción de un discurso no puede verse perjudicada o limitada del todo, si el lector no posee una previa experiencia con textos que se actualizan como citas explícitas o aludidas en el discurso que se analiza, pues por abierta que resulte una obra, su coherencia interna permite la salvedad del texto como unidad. Digamos, más bien, que la competencia intertextual enriquece, prolifera, una gama de sentidos que un discurso conserva siempre en estado potencial.

Cuando señalamos que un discurso no existe sin la reciprocidad de los otros, nos vemos enfrentados a una realidad discursiva que de antemano sabemos que nos sobrepasa. El intérprete debe disponerse con una apertura mental que le permita hacer frente a "la potencialidad semiótica que despliega ante sus ojos una abigarrada galaxia de intertextos" (Rojo 88). Por esto mismo, para efectos de dicho ejercicio crítico, el intérprete debe valerse más bien de su experiencia, que en parte lo obliga a la permanente actualización de su enciclopedia, competencia lectiva y cultural en general. 
Recordemos que los intertextos no se restringen por familias de género o disciplinas. Abarca, si cabe decirlo, toda la constelación interdiscursiva que conforma nuestra cultura.

Por otra parte, no debe olvidarse que una pretendida crítica intertextual no se limitará a la mera detección de otros textos con los que, creemos, guarda alguna relación significativa; pues ya plantear aquellos intertextos como significativos involucra no solo detectarlos -lo que más bien se parecería a la antigua crítica de influencias-, ni menos pretender, con ello, restarle originalidad al texto que es motivo de nuestro análisis (la misma teoría de la intertextualidad evidencia la poca consistencia de aquel pretendido atributo estético); sino más bien, establecer los alcances e implicancias de dicha relación. Es decir, cómo un texto está leyendo al otro; de qué forma se enriquecen mutuamente en su potencial de sentidos; cómo se genera la dinámica de interacción entre los textos; cuál es el lugar, la razón, los elementos contextuales que justifican dicha referencialidad (el horizonte de expectativas, por ejemplo).

En razón de esto último, es necesario señalar que cualquiera sea la lectura que del texto hagamos, esta debe corresponder a una interpretación justificable en virtud de nuestro análisis, y no a una simple utilidad que al texto le demos, por muy enriquecedora, motivante y aceptable que esta sea ${ }^{7}$.

"Un texto es un producto cuya suerte interpretativa debe formar parte de su propio mecanismo generativo: generar un texto significa aplicar una estrategia que incluye las previsiones de los movimientos del otro" (Eco 79). Esto significa que por muy original que resulte una interpretación en virtud de ciertas relaciones intertextuales, esta debe estar sostenida, justificada en el texto mismo, es decir, avalada en el estrato indicial de este. Por lo mismo, creemos importante considerar que la crítica intertextual requerirá, al menos en algunos aspectos, de lo que conocemos como análisis intratextual (establecer las relaciones entre los elementos que constituyen la unidad del texto), pues la interrelación entre los estratos fónicos, gramaticales y semánticos determina tanto la composición como el significado textual. Con ello, podremos respaldar con legítima evidencia, cualquier alcance que a nivel intertextual queramos proponer.

7 Para leer sobre la diferencia entre el uso y la interpretación de un texto, revisar el libro de Umberto Eco, Lector in fábula. 


\section{Lugar de Rimbaud y César Vallejo en la poesía de Gonzalo Rojas}

Conforme con las ideas que sobre intertextualidad hemos desarrollado, retomemos lo que hemos planteado en la introducción con respecto a los objetivos y motivaciones de este artículo. Como ya lo señalamos, hemos tomado dos autores que consideramos claves dentro del horizonte de expectativas que dispone la obra de Gonzalo Rojas: Arthur Rimbaud y César Vallejo. Al decir de Coddou:

La poesía de Gonzalo Rojas se nos ofrece como una rigurosa y elaborada conciencia autotextual que, entre otras manifestaciones -por ejemplo- el cruce de múltiples modalidades discursivas, encuentra, en el diálogo que ella establece con la obra de otros poetas, una forma de realización que te lleva a lograr una sorprendente singularidad de voz (Proyección 1).

Podemos decir que aquella singularidad de la que nos habla el crítico se manifiesta, al menos en la relación con Vallejo, no en distanciamiento, sino en un profundo parentesco. En el mismo artículo, Coddou estudia la proyección del poeta peruano en la obra de Rojas, destacando, entre varios aspectos, el intento de alterar la sintaxis con fines expresivos. Esto puede significar una suerte de escritura diseminada que expresaría: la fragmentariedad del mundo; un ansia interrogativa recurrente en su poesía; el arraigo idiomático en el castellano que motiva una polisemia desbordante; la utilización de expresiones que no pertenecen a lo estrictamente poético (lo que se manifestaría en la coexistencia de metáforas coloquiales y de invención); o la mirada a la infancia como motivo recurrente de escritura, entre otros aspectos.

Considerando estas observaciones, nos falta señalar que la presencia de Rimbaud y Vallejo en la poesía del autor chileno también se manifiesta a través de su mención específica en diversos poemas. Ambos autores, por ejemplo, aparecen con sendos poemas dedicados. En homenaje, uno, y/o conmovedora elegía, el otro. Podríamos señalar que los autores ahora mencionados forman parte de aquella gama autorial diversa que constituye las referencias intertextuales de las que dispone la obra de Rojas y que el poeta no procura solapar, sino más bien otorgar a modo de indicios. Una escritura en clave que resguarda, para el lector, al menos la salvedad de una parcial interpretación. En este sentido, mientras Voyelles, aquel paradigmático poema de Rimbaud, correspondería a un antecedente obligatorio para un pretendido análisis intertextual, El dolor de las cinco vocales, minimalista 
soneto escrito por César Vallejo, resultaría un referente también ineludible, pues como alguna vez lo señalaría el mismo Gonzalo Rojas: "de él venimos todos", aludiendo al poeta de Los Heraldos Negros.

\section{Algunas consideraciones Sobre el SONEto de Vallejo}

En un apartado de su tesis doctoral, Walter Hoefler se detiene en el análisis del soneto de Vallejo ("El dolor de las cinco vocales"). El exhaustivo análisis de Hoefler nos ha permitido dilucidar muchas ideas que en este artículo exponemos. De hecho, hemos asumido diversas apreciaciones acerca del soneto vallejeano expuestas por el crítico, como la eventual relación con el soneto rimbauldeano o la consideración del poema como soneto, a pesar de su minimalismo monosilábico. Estas y otras ideas han sido utilizadas como base para la formulación de las nuestras.

Al destacar que su valor poético radicaría, por un lado, en su intertextualidad con el poema de Rimbaud, Hoefler considera que dicha relación no parece inclinarse por discutir o refutar al poema francés, ya que parece ser más bien una conexión de carácter alusivo, una referencia que permitiría relativizar, en cierta medida, un "problema central biográfico" aludido en el poema y que tiene que ver con una relación amorosa con la "Otilia Limeña" (Hoefler 443). A su vez, el poema perseguiría "reducir la complejidad" del soneto de Rimbaud. Esto, justificado por el minimalismo que manifiesta el soneto peruano en comparación con la magnitud del poema francés.

Por nuestra parte, creemos que también se puede pensar la relación entre ambos poemas en términos aún más dialécticos y comprender el soneto de Vallejo a la luz de una posible respuesta o negación frente al poema de Rimbaud. Consideramos esta apreciación, a partir de las inferencias que permite la exigüidad de los cuartetos iniciales y de lo decisivo que resulta tanto el verbo inaugural del poema, como el adverbio de negación que cierra el segundo cuarteto. Se trataría, eso sí, de una negación no intencionada, sino más bien impuesta o resignada, si se prefiere. Creemos apropiada dicha adjetivación, al considerar que la conjunción pues, que inicia el segundo cuarteto, en este caso parece funcionar como una conjunción con valor condicional que, perfectamente, puede indicar una actitud de resignación por parte del hablante: “ves/lo/que/es pues/yo/ya/no”. Desde esta nueva aproximación, la policromía vocálica propuesta en el soneto rimbauldeano, entendida ahora como la atribución de una propiedad lumínica a las vocales, resultaría una experiencia 
velada ${ }^{8} \mathrm{o}$ incluso imposible en el soneto vallejeano. Esto, a raíz de la ceguera que es posible inferir en el sujeto de la enunciación, pues como se nos indica en el segundo cuarteto, éste ha dejado de ver lo que antes ${ }^{9}$ veía.

Entendido de esta forma, también advertimos la posibilidad de que los tercetos puedan indicarnos la causa de dicha ceguera ("la/ cruz/ da/luz/sin/ fin"), pues la lectura de los versos en continuidad, conduce a sostener, por necesidad de coherencia semántica a la vez que sintáctica, la presencia tácita o implícita de una conjunción de causalidad del tipo:

$\left.\begin{array}{l}\text { A } \\ B\end{array}\right\}$ El efecto o consecuencia (la imposibilidad de ver lo que es) Por motivo o razón de

$\left.\begin{array}{l}C \\ D\end{array}\right\}$ La causa (la cruz que ilumina sin fin)

Lo relevante es que tal como aparece en estos versos, se trata de una ceguedad cuya causa es una luz intensa e incesante, una luminosidad tan fuerte que no deja ver, y que proviene de una fuente que ha sido identificada con un símbolo: la cruz. Pues bien, si el soneto de Rimbaud es, conforme a lo que hemos advertido, un soneto luminar, y asumiendo que el soneto vallejeano "no cita por azar la palabra vocal" (Hoefler 437), ¿será posible considerar que la cruz a la que alude el poema de Vallejo sea también (pues esto no descarta ninguna de las otras interpretaciones posibles) una alusión en clave al soneto del poeta francés?

No creemos descartable esta idea si consideramos que la cruz, como símbolo del cristianismo, es también expresión de padecimiento, de allí que sea utilizada en rituales de carácter fúnebre. No olvidemos considerar el cruce

8 De todas las importantes acepciones para esta palabra, nos quedamos con la siguiente, por ser de sobremanera pertinente para nuestras intenciones. "Borrarse total o parcialmente una imagen fotográfica por la acción indebida de la luz" (D.R.A.E).

9 El ya, que en el poema ocupa el séptimo verso, es a veces utilizado como un adverbio de tiempo que aunque en presente, alude también a un tiempo pasado (D.R.A.E.). 
o la intersección de los dos ejes como el quinto punto de la cruz. Léase en este contexto, el padecimiento de las cinco vocales.

Desde otra perspectiva, podríamos entender también la cruz como una suerte de diagramación simbólica del soneto. Por cada extremo de ella, las cuatro estrofas de este. Pensemos, por ejemplo, que el primer verso en el soneto de Rimbaud nombra secuencialmente las cinco vocales, lo que podría estimarse como el punto de reunión de todas ellas, algo similar a lo que podría ser la intersección de los dos ejes en la cruz.

De cualquier forma, la atribución del dolor a las cinco vocales, aspecto exclusivamente verbal, puede entenderse como la proyección lingüística de un dolor padecido antes por el sujeto de la enunciación. Dolor que como se señala en el análisis que estamos citando, quizás tiene que ver con una experiencia amorosa aludida en los paratextos y que no descarta también una forma de "acuerpamiento de cierto dolor universal" (Hoefler 436), característico en Vallejo. Lo escueto del soneto y la indeterminación de sus versos permiten esta multiplicidad de sentidos ${ }^{10}$. Lo que por nuestra parte deseamos añadir, ya que no queremos desvincularnos de la evidente alusión al soneto de Rimbaud, es que dicho dolor puede relacionarse, también, con una experiencia explicable como la pérdida del origen bautismal o iniciático otorgado por un vate-Rimbaud ${ }^{11}$. Esto, pensando en que tanto Vallejo como Rojas, quizás más

10 Con respecto a la idea de indeterminación que puede propiciarse a través de la utilización adecuada de algunos pronombres, Rojas sostiene que el pronombre "esto", por ejemplo, indica "lo que no alcanza a decirse, el "esto" de lo indecible de los poetas, lleno de resonancias. Es la ambigüedad de la poesía, porque nunca un poeta llega a la torpeza de decir que una cosa es así, exactamente". También en el mismo texto, señala más adelante: “"Esto" nace como puede nacer "lo" que es otro neutro: "Lo mohoso es el cuchillo", por ejemplo" (Piña 108). Estas ideas resultan relevantes, en cuanto pueden aplicarse perfectamente a Vallejo y específicamente al poema que ahora analizamos, pues la indeterminación del poema también pasa por la utilización y ubicación del pronombre lo que sostiene el segundo verso. No sabemos con exactitud qué es aquello que el hablante ya no puede ver.

11 Sobre el carácter de augur en el sujeto poético de "Voyelles", bástenos recordar los dos primeros versos: "A negra; E blanca, I roja, U verde, O azul: diré,/Vocales, algún día su virtual nacimiento”. Sobre la idea del poeta iluminado, revisar el ensayo de Eduardo Anguita titulado "Rimbaud pecador", incluido en el libro Anguitología. Algo pertinente para nuestros fines podemos extraer de la siguiente cita: "Sus imágenes poéticas mismas son casi exclusivamente visuales: y aunque se propuso crear un lenguaje accesible a todos los sentidos, predomina lo visual" (Anguita 196). 
éste último, puedan ver en el poeta francés, un símbolo o arquetipo del poeta iluminado, del vidente, y en su soneto, una manifestación de ello.

\section{CATEgorías de ANÁLisis}

Como ya habíamos señalado, para la realización de este trabajo hemos recurrido a la revisión bibliográfica crítica. Los comentarios y alcances sobre las distintas ideas planteadas por otros autores y sobre fragmentos de otros poemas de Gonzalo Rojas, que hemos encontrado pertinentes para efectos de esta investigación, serán discutidos debidamente en la sección siguiente.

Para poder determinar la forma en que la intertextualidad pudiera materializarse en el texto mismo y así encontrar indicios que permitan fundamentar dicha relación, hemos construido una serie de cuadros esquemáticos que nos van a permitir analizar algunos aspectos que consideramos relevantes:

1. Presencia de las vocales. Estos fonemas son el factor principal que justificaría la intertextualidad entre los tres textos. Para determinar con claridad este aspecto y considerar la forma en que dichos fonemas pudieran destacar en los poemas, hemos procedido de la siguiente manera:

a) Realización de un registro estadístico sobre la frecuencia de aparición de cada vocal.

Figura 1

Frecuencia estadística de las vocales

\begin{tabular}{|c|c|c|c|}
\hline vocales & Rojas & Vallejo & Rimbaud $^{12}$ \\
\hline $\mathrm{a}$ & 117 & 3 & 33 \\
\hline $\mathrm{e}$ & 111 & 4 & 90 \\
\hline $\mathrm{i}$ & 60 & 4 & 38 \\
\hline $\mathrm{o}$ & 52 & 3 & 27 \\
\hline $\mathrm{u}$ & 38 & 4 & 26 \\
\hline
\end{tabular}

12 Para efectos de este registro estadístico, hemos utilizado el poema Vocales en su idioma original. 
b) Registro de los recursos tipográficos que puedan resaltar alguna de las vocales.

Figura 2

Evidencia tipográfica

\begin{tabular}{|c|l|l|l|}
\hline Vocales & Rojas & Vallejo & Rimbaud \\
\hline a & No se evidencia & No evidencia & $\begin{array}{l}\text { Destaca con tipografía } \\
\text { mayúscula dos veces en forma } \\
\text { individual }\end{array}$ \\
\hline $\mathrm{e}$ & $\begin{array}{l}\text { Destaca con tipografía mayúscula } \\
\text { en las palabras Especie y Espíritu }\end{array}$ & No evidencia & Idem \\
\hline $\mathrm{i}$ & No se evidencia & No evidencia & Idem \\
\hline $\mathrm{o}$ & No se evidencia & No evidencia & $\begin{array}{l}\text { Destaca en mayúscula cuatro } \\
\text { veces. Tres en forma individual } \\
\text { y una en la palabra Omega }\end{array}$ \\
\hline $\mathrm{u}$ & No se evidencia & No evidencia & $\begin{array}{l}\text { Destaca con la tipografía } \\
\text { mayúscula dos veces en forma } \\
\text { individual }\end{array}$ \\
\hline
\end{tabular}

2. Elaboración de ejes o campos semánticos. Esto consiste en agrupar una serie de lexemas que forman parte del texto y que pueden reunirse bajo significados o connotaciones similares. Para ello, hemos utilizado las siguientes categorías:

a) Campo semántico vinculado a las asociaciones cromáticas. La cromática es un factor posible de vinculación, puesto que hemos considerado al soneto de Rimbaud como texto base (hipotexto). Por lo mismo, utilizamos la gama de colores impuesta por el poeta francés en su soneto, con el fin de detectar las posibles asociaciones cromáticas presentes en el poema de Rojas (negro, blanco, rojo, verde y azul).

Figura 3

Campo semántico de las asociaciones cromáticas

\begin{tabular}{|l|l|l|l|}
\hline Colores & Rojas & Vallejo & Rimbaud \\
\hline Negro & estas vocales/oscuras & No registra & A negra \\
& & & Negro corsé \\
& & & Moscas brillantes \\
& & & Golfos sombrios \\
\hline
\end{tabular}




\begin{tabular}{|l|l|l|l|}
\hline Blanco & $\begin{array}{l}\text { mi vertiente/de diamante } \\
\text { página/ de piel } \\
\text { del ritmo/de marfil } \\
\text { figuralespléndida, orquidea } \\
\text { de otra música/ de nieve }\end{array}$ & Luz/ sin/fin & $\begin{array}{l}\text { E blanca } \\
\text { Candor de vapor y tiendas } \\
\text { Lanzas de altos glaciares, reyes } \\
\text { blancos, umbelas }\end{array}$ \\
\hline Rojo & $\begin{array}{l}\text { Llama } \\
\text { Lengua }\end{array}$ & No registra & $\begin{array}{l}\text { I roja } \\
\text { Purpúreas, sangre escupida } \\
\text { Hermosos labios } \\
\text { Violeta el rayo de sus ojos }\end{array}$ \\
\hline Verde & No registra & $\begin{array}{l}\text { U verde } \\
\text { Mares verdes } \\
\text { Paz de pastos }\end{array}$ \\
\hline Azul & Hija del mar & No registra & Oazul \\
\hline
\end{tabular}

b) Campo semántico vinculado a la experiencia de los sentidos. En el caso de Rimbaud, las asociaciones cromáticas de las vocales devienen en una asociación sinestésica, y en el caso de Vallejo, la pérdida de la experiencia visual es, al parecer, un motivo central en el poema.

Figura 4

Campo semántico de la experiencia sensitiva

\begin{tabular}{|l|l|l|l|}
\hline $\begin{array}{l}\text { Experiencia de los } \\
\text { sentidos }\end{array}$ & Rojas & Vallejo & Rimbaud \\
\hline $\begin{array}{l}\text { Experiencia } \\
\text { auditiva }\end{array}$ & $\begin{array}{l}\text { Cuerda/para oir/el } \\
\text { viento }\end{array}$ & $\begin{array}{l}\text { No } \\
\text { registra }\end{array}$ & $\begin{array}{l}\text { Supremo clarín de estridores extraños } \\
\text { Silencios atravesados por Ángeles. Por } \\
\text { Mundos }\end{array}$ \\
\hline Experiencia táctil & $\begin{array}{l}\text { Página/de piel } \\
\text { Manos/ que amé }\end{array}$ & $\begin{array}{l}\text { No } \\
\text { registra }\end{array}$ & Escalofrios \\
\hline $\begin{array}{l}\text { Experiencia } \\
\text { Olfativa }\end{array}$ & $\begin{array}{l}\text { Fragancia/de otra } \\
\text { música }\end{array}$ & $\begin{array}{l}\text { No } \\
\text { registra }\end{array}$ & Crueles hedores \\
\hline $\begin{array}{l}\text { Experiencia } \\
\text { Gustativa }\end{array}$ & $\begin{array}{l}\text { Lengua/de amor/ } \\
\text { viva }\end{array}$ & $\begin{array}{l}\text { No } \\
\text { registra }\end{array}$ & Hermosos labios en ira \\
\hline Experiencia visual & $\begin{array}{l}\text { Velocidad/Ciega/ } \\
\text { del sol } \\
\text { La translucida } \\
\text { La transparencia }\end{array}$ & $\begin{array}{l}\text { Ves/lo/ } \\
\text { que/es } \\
\text { pues/yo/ } \\
\text { ya/no }\end{array}$ & $\begin{array}{l}\text { A negra, E blanca, I roja, U verde, O } \\
\text { azul } \\
\text { Violeta el rayo de sus ojos }\end{array}$ \\
\hline
\end{tabular}




\section{ANÁLISIS Y DISCUSIÓN}

\section{CONSIDERACIONES PRELIMINARES}

En cuanto a la frecuencia estadística de las vocales, la mayoritaria reiteración de las dos primeras vocales en el texto de Rojas, creemos que se vincula, principalmente, con aspectos característicos del estilo y la poética del autor. Las vocales son sonidos que se producen dejando salir libremente el aire, sin obstrucción. Por esto mismo, el tratamiento que Rojas realiza de estos fonemas tiene que ver con lo que Coddou dio en denominar "trepidación fisiológica de su poesía" (Rojas, Obra Selecta LXVIII). Un ejercicio de aire-asfixia que guarda relación con lo que podría denominarse una poética de la tartamudez. Aspecto que, dicho sea de paso, la crítica ha sabido tratar con pertinente rigurosidad. De todas formas, no sería inapropiado detenernos en ello un momento. Consideremos, como ejemplo, lo que sucede con la vocal /a/. Si recordamos que el total de palabras que posee el texto es 192, entonces admitiremos que esta vocal se distribuye mayoritariamente en el poema, lo que puede entenderse como la evidente utilización de un recurso de aliteración. Siendo esto en cuanto al plano de la expresión, connotativamente la sonoridad de la /a/ deviene en alivio, respiro, aire, desahogo en el ritmo poético. Por subjetivas que parezcan estas apreciaciones, las consideramos pertinentes en cuanto significan una asimilación de las potencialidades fónicas del lenguaje. Aspecto que, dicho sea de paso, constituye algo muy explorado por Rojas. Justificamos esta idea, a partir de la lectura de un poema titulado, precisamente, “Asma es amor" (Rojas, Antología 315). En este poema, la utilización del mismo recurso explora, esta vez, una connotación opuesta. Si la presencia de Hilda en el discurso poético es aire y respiro, como sucede en "Vocales para Hilda", su ausencia, tal como sucede en el poema que ahora mencionamos es "asma" y el hablante se "ahoga en su no aire".

La tipografía (figura 2), por otro lado, nos evidenció algo decididamente más interesante para los fines de este trabajo. La presencia mayúscula de la /e/ en el poema de Rojas, hecho que la destaca del resto de las vocales, resulta un indicio clave, pues coincide con el predominio, en el mismo poema, del color blanco. Dicha relación ha sido detectada a partir de las asociaciones cromáticas presentes en "Vocales para Hilda" e indicada debidamente en la figura 3. La razón por la que este dato es relevante, radica en una vinculación con la policromía de los versos de Rimbaud, ya que en este poema la $e$ se constituye, precisamente, como la vocal alba: “...E blanca (...) candor de 
vapores y tiendas/Lanzas de altos glaciares, reyes blancos, umbelas/Escalofrios..." (Rimbaud 165-167).

Establezcamos, por lo pronto, cierta simbología asociada culturalmente al blanco (Becker 53). Sabido es que el blanco no es un color, de allí que ocupe un lugar especial en la escala cromática. El blanco es la suma de todos los colores y, por lo mismo, se vincula con lo absoluto, el principio y el fin, la reunión de los extremos. También es el color de la luz y se considera como color sagrado en general.

Por otra parte, el eje semántico vinculado a la experiencia de los sentidos (figura 4), nos señala que la ausencia de una experiencia visual, evidenciada en el poema de Rojas, es un dato que coincide, si recordamos lo expuesto en el marco teórico, con la ceguera insinuada por el sujeto de la enunciación en el soneto de Vallejo. En Vocales para Hilda, el sujeto poético intenta captar a la figura femenina a través de una experiencia sensorial totalitaria, idea que confirman los versos registrados en la figura 4, pero que parece frustrarse o tornarse imposible, pues la única experiencia sensitiva no mencionada por asociaciones directas, sino más bien por negación, es la experiencia visual. Palabras como translúcida o transparencia, o la mención explícita a la ceguera en el verso decimonoveno, parecen confirmar la imposibilidad de dicha experiencia visual.

Con el fin de colocar en dinamismo cada uno de estos datos y proporcionar mayor claridad en la exposición de las ideas, analizaremos las relaciones aquí expuestas conforme a los puntos de distanciamiento y encuentro entre los poemas que relacionamos, vale decir, puntos de divergencia y convergencia interpretativa.

\section{Puntos De Divergencia}

En un poema titulado "Concierto", en donde Rojas nombra a los autores que al parecer considera trascendentes, es el poeta francés quien encabeza aquel index nominum que manifiesta la compleja enciclopedia de un Gonzalo Rojas, ante todo, lector. "Rimbaud/pintó el zumbido de las vocales” (Rojas, Antología 169). Lo que aquí parece sostener Rojas, en su particularísimo lenguaje, es que Rimbaud atribuye colores a elementos que son más bien de carácter auditivo, fonemas en estricto rigor. De allí la metáfora del zumbido. Esto es lo que se conoce con el nombre de sinestesia y que consiste en un entrecruzamiento de experiencias sensitivas, hecho que también puede ser abordable como figura retórica. 
También es cierto que frente a esta suerte de bautismo cromático realizado por Rimbaud, el poeta chileno parece guardar cierta distancia. En algunos poemas habla de Vocales ciegas (Rojas, Antología 91), expresión no muy ajena a la de vocales oscuras, presente en el poema que analizamos y que nos manifestaría el distanciamiento y oposición en torno a las vocales coloreadas $\mathrm{y}$, por ende, iluminadas de Rimbaud.

Consideremos, por otra parte, la connotación opuesta que aparece indicada en la figura 4, en relación con la experiencia olfativa específicamente. Si Rimbaud en su soneto habla de crueles hedores, Rojas preferirá una expresión sinestésica del tipo: fragancialde otra música, por ejemplo.

Otra diferencia surge de la lectura comparativa de los paratextos. Si leemos los títulos del soneto francés y del poema de Rojas, es posible advertir que el título de este último alude, preferentemente, a una dedicatoria, lo que también puede comprenderse como un gesto de desprendimiento por parte del hablante. El desprenderse de algo y otorgarlo a modo de obsequio, una ofrenda en todos sus sentidos posibles, incluso el religioso, y que a su vez se proyectaría como una exaltación del sujeto del enunciado. Tributo u homenaje, deducible a partir de un paratexto que privilegiaría un sentido laudatorio en el poema. En este sentido, resulta interesante proponer que la lectura lineal del título como "dedicatoria", no descarta una lectura en oblicuidad que evidenciaría un gesto oculto y absolutamente inverso de "apropiación". Situándonos ahora en la lectura intertextual del poema o restrictivamente de su paratexto, vemos cómo éste no solo connota "ofrenda", sino que también deviene en un sintagma nominal cuyo complemento preposicional, "para Hilda", lo salvaguarda de una eventual homologación con el poema de Rimbaud, también titulado "Vocales" sino que también se apropia y quizás distancia, de las vocales alguna vez poetizadas por el escritor de "Iluminaciones".

Con el objetivo de fundamentar aún más estas ideas, consideramos apropiado mencionar algunos ejemplos extraídos de otros poemas del autor chileno. En "Fosa con Paul Celan" aparecen los siguientes versos: "meo/por Rimbaud contra el cielo sin heliotropos/ni consentimiento, /de estrellas" (Rojas, Antología 147). Versos estos, que dialogan también por oposición con un poema de Rimbaud titulado "Oraison du soir", que en la traducción 
que utilizamos aparece como "Oración vespertina”: “(...) meo, alto y muy lejos,/hacia los cielos brunos/con el asentimiento, por supuesto,/de los enormes heliotropos (...)" (Rimbaud 125).

Algo similar sucede con un poema como "Diáspora 60", en donde ya su apertura es una clara reminiscencia al poema "Vocales" de Rimbaud, pero esta vez caótica en cuanto a las asociaciones que vinculan letra y concepto, y distanciándose estructuralmente del orden y la armonía que aquel soneto manifiesta. No son vocales las que nombra, sino consonantes. Idea que en conformidad con la poética de Rojas puede sugerir asfixia o tartamudez, en cuanto a que el sonido consonántico es un sonido que surge al obstruir la salida del aire. Dicha intención podría aclararse a partir de las connotaciones histórico-políticas que del título podemos inferir.

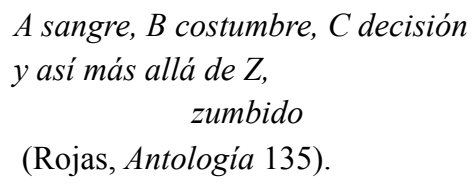

Al parecer, se trata de una relación dialéctica que no desestima la disidencia. Evocación y distanciamiento en torno a la obra y a la figura de Rimbaud. Por muy pertinente que nos resulte esta hipótesis, sabemos que ampliarla a un corpus más extenso del autor chileno escapa a las pretensiones de este trabajo. Dejamos, de todas formas, planteada dicha conjetura para efectos de un posible estudio ulterior.

\section{LAS Voces Se oyen Al unísono. Puntos De CONVERGencia}

Aunque a diferencia del soneto francés, los poemas de Vallejo y Rojas no tematizan directamente las vocales, debemos señalar que en los tres poemas ellas poseen un lugar privilegiado en lo que a los paratextos (títulos) respecta. Ya sea como lexema único en el caso del soneto francés; como elemento genitivo en el que recae una experiencia doliente, a propósito del poema de Vallejo; o como sujeto de un sintagma nominal que funciona a modo de ofrenda, en lo que al poema de Gonzalo Rojas se refiere.

Por otro lado, consideremos el vínculo entre las dedicatorias que, a modo de paratextos, aparecen en los poemas de Rojas y Vallejo. Ambos están dedicados a una mujer. En el caso de Vallejo, el poema tiene un paratexto que funciona a modo de dedicatoria "a Otilia". En Rojas, el nombre femenino 
"Hilda", es incluido en un paratexto que podríamos denominar de mayor nivel jerárquico; el título.

Podríamos señalar que a nivel de contenido, el diálogo polifónico entre estos poemas se vuelve más complejo a medida que se entrecruzan los poemas de Vallejo y Rojas. Si los puntos de inflexión o los espacios de divergencia se hacían más notorios en la relación con Rimbaud, los puntos en donde las voces se encuentran en armonía antes que en disonancia, la complicidad entre poéticas y poetas, se torna evidente a medida que se estrechan ambos poemas latinoamericanos. Para profundizar en esto, hemos considerado algunos puntos importantes que forman parte de la poética de Gonzalo Rojas.

Indudablemente, la ceguedad es un motivo recurrente en Rojas. Un aspecto que también queda estrechamente vinculado al símbolo del relámpago, ampliamente trabajado por la crítica. "El relámpago" tiene que ver con una aspiración metafísica en su obra, lo que se ha dado a conocer como la vertiente luminosa de su poesía. Según Coddou:

Lo que mueve al poeta es el ánimo de acceder a la realidad: no la aparente de la superficie inmediata, sino esa otra detrás suya, lo que el sufismo llama El Alma del Universo, traducible como lo absoluto, el Todo, la Fuente del Ser. Y esto se logra por la iluminación, por lo demás difícilmente permanente (Rojas, Obra Selecta XXX).

Aquella idea de una iluminación difícilmente permanente, que nos menciona el crítico, es lo que vuelve pertinente el símbolo del relámpago en cuanto fenómeno lumínico e instantáneo. Al respecto, Rojas nos señala lo siguiente: "El relámpago: lo dijo Heidegger y Heráclito. Es ese abrir y cerrar los ojos un instante" (Cit. en Piña 108). De allí que otro concepto central en la poesía del autor, "lo oscuro", devenga en un principio necesario que resalta por oposición, la fulminante luminosidad del relámpago. Sobre el simbolismo de lo oscuro, Montejo propone, entre varias acepciones distintas, la siguiente:

(...) el hombre, al igual que dios, es invisible. El hombre es, pues, fatalmente oscuro. Solo mediante el relámpago del poema se logra, cuando se logra, atisbar algo de la claridad que es como decir la identidad de quien lo escribe, a la vez que puede servirnos para columbrar la de quien lo lee" (Rojas, Poesía Esencial 15).

De acuerdo con esta cita, advertimos que las implicancias filosóficas de estos símbolos no olvidan su raigambre literaria o poética. El relámpago tiene 
que ver, entonces, con el poema y con su posibilidad de iluminar o revelar. Rojas hablará de "oficio ciego" para referirse al ejercicio o escritura poética (Antología 82). En otros poemas, el autor hablará de "vocales ciegas" (Antología 91), expresión que como ya hemos advertido, es similar a la de "vocales oscuras". Lo cierto es que las expresiones que aquí mencionamos deben considerarse, más bien, como ejemplos excepcionales en la utilización de una figura retórica en particular: la hipálage. Esta figura consiste en atribuir a un objeto, por lo general a través de un adjetivo, el concepto que conviene a un término que en aquel texto le es cercano. No olvidemos que el eje semántico asociado a la experiencia de los sentidos evidenció la ausencia de una experiencia visual por parte del sujeto de la enunciación, lo que permite comprender que la atribución de la oscuridad como adjetivo a las vocales significa, por medio de una hipálage, una mención indirecta a la ceguedad del hablante. Lo mismo sucede con aquel verso que recién mencionábamos: "me abrumo len las vocales ciegas". Expresión que, sin la utilización de la hipálage, puede formularse como "Ciego, me abrumo en las vocales". Aclaradores resultan al respecto estos versos de Quevedo en donde también se resalta dicho recurso retórico:

\title{
Naces, Aminta, a Silvio del ocaso \\ En que me dejas sepultado y ciego; \\ Sígote obscuro $^{14}$ con dudoso paso. \\ (Quevedo, 370)
}

\begin{abstract}
Ahora bien, ninguna de estas ideas resulta ajena al soneto vallejeano, pues su contenido titular puede resumirse, por ejemplo, en una hipálage del tipo Vocales dolientes. De esta forma, confirmamos que dicho dolor resulta ser, como lo habíamos señalado, la proyección lingüística de un padecimiento más bien visceral, es decir, atribuible antes al sujeto de la enunciación.

Asumiendo las ideas aquí expuestas, es necesario considerar que el motivo de la ceguera, en Rojas, es abordable al menos desde dos perspectivas diferentes. Por un lado, se trata de la ceguedad como ausencia de luz, metáfora de la penumbra o de lo oscuro antes mencionado, y que poéticamente Rojas referirá como un "llegar a tientas al gran palimpsesto de lo uno" (Rojas, Antología 88). Por otro lado, dicha ausencia visual también tiene que ver con
\end{abstract}


la experiencia de una luminosidad intensa y enceguecedora, una lumínica calcinante que guarda relación con la imposibilidad de prolongar la luz del relámpago más allá de un mero instante. Idea que en su formulación poética, y de evidente parentesco con el soneto vallejeano, aparece encabezando un poema titulado "El sol y la muerte":

Como el ciego que llora contra un sol implacable, me obstino en ver la luz por mis ojos vacíos, quemados para siempre.

(Rojas, Antología 17)

Creemos que ambas ideas aparecen y coexisten en "Vocales para Hilda". Consideremos, para ello, que la reiteración mayoritaria de las dos primeras vocales en dicho poema (figura 1), podría estimarse como un indicio en clave que nos remita a la dicotomía cromática que Rimbaud dispusiera para ambos fonemas: negro y blanco. Colores que ahora contextualizados en la poética de Rojas adquieren una nueva connotación simbólica. De esta forma y tal como lo habíamos señalado previamente, el blanco también es comprendido, a nivel simbólico, como color de la luz en general. Por lo que su predominio o aparición insistente en el poema de Rojas, por lo menos en cuanto a las asociaciones semánticas que ya hemos advertido en la figura 3 , puede ser-de acuerdo con los argumentos que hasta aquí se han desarrollado-, un indicio que también nos remita a aquella luz intensa que imposibilita la visión en el poema de Vallejo ${ }^{15}$.

De acuerdo con estas ideas, si consideramos la estructura de ambos poemas como un elemento también significante, pues se trata de poemas escritos en delgadez y que construyen visualmente una linealidad vertical, surge también un sentido posible para dicha disposición tipográfica. Su verticalidad es haz de luz en Vallejo (relación entre plano del contenido y plano de la expresión) o relámpago, si nos remitimos a la poética de Gonzalo Rojas. Al

15 Es importante no pasar por alto, a propósito de esto último, cierta idea asociada al sol, pues manifiesta una diferencia entre Vallejo y Rojas. El cristianismo, agónico y todo, es centro en la poesía del peruano, es su dolor. En cierta medida, el mismo rol semántico cumple la cruz y el sol en ambos poemas (fuente de energía). Recordemos que en el poema de Rojas el astro es también mencionado, solo que en el caso del chileno, la divinidad es numen, es decir, sin religión privativa. De allí la pertinencia del sol, antes que la cruz, como símbolo también divino en Rojas. 
respecto, es significativo recordar los siguientes versos vallejeanos: "la $\mathrm{Luz}$ es tísicaly la sombra gorda (Obra poética Completa 115).

Entonces, si nos sabemos privados de la visión ¿qué nos queda? La respuesta no podemos dejarla esperar: sonido, música. Recordemos que la musicalidad es un aspecto determinante para una poética que como la de Rojas, es predominantemente auditiva. No olvidemos aquella advertencia prologal que nos propusiera el mismo autor: "No al lector, al oyente" (Nómez 272). Musicalidad que en el poema de Rojas es manifiesta tanto en el plano del contenido como en el plano de la expresión ${ }^{16}$, ya que no solo debemos considerar los recursos de aliteración, rima o ritmo que utiliza el poema, sino también el hecho de que la figura femenina o sujeto del enunciado es identificado, también, con caracteres o elementos musicales.

\begin{tabular}{|l|}
\hline Elementos relacionados con la \\
música y con los que se identifica a la \\
figura femenina \\
\hline Vibrante \\
Cítara \\
Arpa \\
Cuerda \\
Alta \\
Acordes \\
Ritmo de marfil \\
Música de nieve \\
\hline
\end{tabular}

Para Coddou, en la poesía de Rojas la oscuridad tiene su símil en el silencio. Otro motivo recurrente en la poética del autor chileno. De esta forma, el poema no solo es un chispazo que acierta una visión fugaz de la realidad, sino algo que también, y de sobremanera, puede llegar a oírse, por instantes. De esta forma, ambas condiciones, la oscuridad y el silencio resultan instancias propicias para una experiencia cercana al misticismo. Tal vez este esquema ayude a aclarar dicha relación:

16 Leer el artículo que escribe Marcelo Coddou: "Enunciación y enunciado en "Vocales para Hilda". En este artículo Coddou se propone estudiar el poema centrándose en dos elementos clave: "uno, la visión de mundo configurada en los procedimientos enunciativos (si Uds. quieren, los significados que constituyen el sistema retórico utilizado) y dos, en la índole misma de estos procedimientos cuya función es comunicar el sentido (o sea, en el proceso de significación)". (Coddou, Enunciación 1). 


\begin{tabular}{|l|l|}
\hline Situación del hablante & Concepción de la poesía \\
\hline Oscuridad & Poesía como el Relámpago \\
\hline Silencio & Poesía como el Zumbido \\
\hline
\end{tabular}

Debemos señalar que esta musicalidad es también evidente en el poema de Vallejo, lo que en parte compensaría aquel dolor expresado a nivel titular, pues desde esta aproximación, la imposibilidad de ver se compensaría con el consuelo de oír. Ya la relativa frecuencia consonántica, que Hoefler analiza de forma específica, es indicio de una musicalidad resguardada, precisamente, por la rima o consonancia vocálica en el soneto. Este es uno de los variados aspectos que vienen a constituir, al decir de Coddou, la "proyección de Vallejo en la poesía de Gonzalo Rojas" (Proyección 1). Al respecto, debemos insistir en que la musicalidad del soneto vallejeano nos recuerda cierta ritmicidad chamánica o altiplánica, andina si se prefiere. Aspecto difícil de explicar teóricamente, pues al decir de Borges: "estas palabras hay que oírlas, no leerlas". Quizás, esta es una referencia a la que también alude Rojas en su poema:

\author{
muchacha \\ mortal, fragancia \\ de otra música \\ de nieve \\ sigilosamente \\ andina.
}

De todas formas, creemos posible que el diálogo aquí propuesto entre los textos se posibilite a partir de la actitud apostrófica que adopta el hablante en el poema de Vallejo. Aquel receptor implícito y a la vez indeterminado ${ }^{17}$ en el soneto del peruano, privilegia una suerte de pregunta abierta ("ves lo que es") ${ }^{18}$. Aprovechando, entonces, las posibilidades permitidas por los mecanismos de producción de sentido y que aquí hemos procurado desarrollar teóricamente, permítanos el lector ahora dejarnos llevar solo por la poesía, pensar que dicha interrogante haya llegado a los oídos de Rojas, y que en su texto el poeta haya respondido: no; no lo veo, pero lo oigo.

17 Aun por medio de la dedicatoria, no debemos considerar que el receptor implícito se reduce privativamente a dicho nombre.

18 Hoefler ya advierte que el cuarteto inicial esconde una tonalidad ligeramente interrogativa, corroborada por la conjunción pues que inmediatamente le sigue. 


\section{CONCLUSIONES}

De los resultados mostrados, de su análisis y de su discusión, se pueden obtener las siguientes conclusiones:

1) Es posible leer "Vocales para Hilda" en relación intertextual con los sonetos de A. Rimbaud y César Vallejo. Dicha vinculación puede comprenderse en una continuidad que se correlaciona, incluso, con la jerarquía cronológica de los textos. Rimbaud otorga colores a las vocales, una cromática bautismal que el sujeto de la enunciación vallejeano pareciera asumir en padecimiento, ya que la propiedad lumínica de las vocales resultaría una experiencia imposible para el hablante, su ceguedad así nos lo confirma. Rojas solidariza con Vallejo, pues en su poema la experiencia visual tampoco existe, al menos no a través de asociaciones semánticas directas. Por su parte, el sujeto poético en el texto de Rojas redime dicho padecimiento, salvaguardando la musicalidad de las vocales, es decir, su magnitud como elementos fónicos antes que icónicos o visuales, y elevándolas en canto de amor; o expresado de otra manera, construyendo con estos fonemas, ahora un poema de carácter amoroso. Con esto, dicho sea de paso, también redime, por extensión, la culpabilidad amorosa que se manifestaría en el posible contenido central autobiográfico del poema vallejeano; ya que independiente de la heterogeneidad onomástica, ambos sujetos del enunciado son femeninos, y el hecho de que en el poema de Rojas este apareciera como componente titular, puede interpretarse como un gesto de ascenso, puesto que a nivel de los paratextos, de una dedicatoria asciende al título. Eventualmente, esto puede interpretarse como gesto de redención para dicha figura femenina, entendida aquí, más bien como arquetipo genérico antes que figura individualizada. Por lo menos, visualmente así pareciera.

2) El análisis aquí propuesto nos ha permitido vislumbrar ciertas características específicas que definen la relación entre la obra de Rojas con la de Rimbaud y César Vallejo. Como lo advertimos, la relación con Rimbaud parece constituirse como una relación de evocación y distanciamiento en torno a su obra. Recordemos que la mayoría de los ejemplos que propusimos como puntos de divergencia interpretativa, tenían que ver con la relación específica entre "Vocales para Hilda" y el soneto de las "Vocales" de Rimbaud; mientras que en los ejemplos que propusimos como puntos de convergencia interpretativa, predominaron, evidentemente, aquellos en los que el diálogo 
con Vallejo se hacía más directo o específico. Si estas apreciaciones son extensibles a toda la obra de Rojas, puede ser motivo para otro trabajo que se desarrolle en esta misma línea. De todas formas, consideramos esta conclusión como una de las más relevantes a las que hemos llegado.

3) Nuestro trabajo contribuye a la actualización del potencial de sentidos que posee el poema de Gonzalo Rojas, pues se concluye que el texto no se reduce a un poema de corte privativamente amoroso. Si bien es cierto que esto no resulta nuevo para la crítica especializada en el poeta, ya que la ubicación de sus poemas es siempre transitoria, y las distintas vertientes en las que suele ordenarse su poesía están siempre en continua interrelación, siendo, así, difícil pensar sus poemas restringidos a un solo campo temático, tampoco es equívoco que la intertextualidad aquí propuesta es, ciertamente, menos evidente. Al menos no es detectable en los estratos superficiales del texto y, por lo tanto, bastante más relevante si es que se logra su decodificación. Por esto mismo, creemos que el análisis aquí propuesto no deja de resultar una alternativa legítima, al momento de aproximarse a la multiplicidad de sentidos que el poema de Rojas nos permite.

\section{BIBLIOGRAFÍA}

Anguita, Eduardo. Anguitología. Santiago de Chile: Editorial Universitaria, 1999.

Becker, Udo. Enciclopedia de los símbolos. Barcelona: Ediciones Robinbook, 1996.

Coddou, Marcelo. "Enunciación y enunciado en "Vocales para Hilda". gonzalorojas.uchile. cl. http://www.gonzalorojas.uchile.cl/estudios/codu2iv.html

"Proyección de Vallejo en la poesía de Gonzalo Rojas". gonzalorojas.uchile.cl. http://www.gonzalorojas.uchile.cl/estudios/codu.html

Eco, Umberto. Lector in fábula (la cooperación interpretativa en el texto narrativo). 1979. Barcelona: Editorial Lumen, 2000.

Hoefler, Walter. "Modelos textuales (géneros y tipos) en la lírica hispanoamericana moderna". Tesis doctoral. Frankfurt, 1994.

Nómez, Naín. Poesía chilena contemporánea. Breve antología crítica. Santiago de Chile: Tierra Firme, 2002.

Piña, Juan Andrés. Conversaciones con la poesía chilena. 1990. Santiago de Chile: Pehuén Editores, 1993.

Quevedo, Francisco de. Obras Completas, poesía original. 1963. Barcelona: Planeta, 1966. Rimbaud, Arthur. Poesías completas. 1997. Madrid: Visor libros, 2005.

Rojas, Gonzalo. Obra selecta. Selección, prólogo, cronología, bibliografía y variantes: Marcelo Coddou. Santiago de Chile: Editorial Ayacucho, Fondo de Cultura Económica, 1999. 
Antología de aire. 1991. Santiago de Chile: Fondo de Cultura Económica, 2004. Poesía esencial. 2001. Santiago de Chile: Editorial Andrés Bello, 2004.

Rojo, Grínor. Diez tesis sobre la crítica. Santiago de Chile: LOM Ediciones, 2001.

Vallejo, César. Obra poética completa. 1982. Madrid: Alianza Editorial, 1999.

Obra poética. Madrid: Archivos, 1988. 
Anexos

Vocales para Hilda

(Gonzalo Rojas)

1 La que duerme ahí, la sagrada,

2 la que me besa y me adivina,

3 la translúcida, la vibrante,

4 la loca

5 de amor, la cítara

6 alta:

7 tú,

8 nadie

9 sino flexiblemente

10 tú,

11 la alta,

12 en el aire alto

13 del aceite

14 original

15 de la Especie:

16 tú,

17 la que hila

18 en la velocidad

19 ciega

20 del sol:

21 tú,

22 la elegancia

23 de tu presencia

24 natural

25 tan próxima,

26 mi vertiente

27 de diamante, mi

28 arpa,

29 tan portentosamente mía:

30 tú,
31 paraíso

32 o

33 nadie

34 cuerda

35 para oír

36 el viento

37 sobre el abismo

38 sideral:

39 tú,

40 página

41 de piel más allá

42 del aire:

43 tú,

44 manos

45 que amé,

46 pies

47 desnudos

48 del ritmo

49 de marfil

50 donde puse

51 mis besos:

52 tú,

53 volcán

54 y pétalos,

55 llama;

56 lengua
57 de amor

58 viva:

59 tú,

60 figura

61 espléndida, orquídea

62 cuyo carácter aéreo

63 me permite

64 volar:

65 tú,

66 muchacha

67 mortal, fragancia

68 de otra música

69 de nieve

70 sigilosamente

71 andina:
72 tú,

73 hija del mar

74 abierto,

75 áureo,

76 tú que danzas

77 inmóvil

78 parada

79 ahí

80 en

81 la transparencia

82 desde

83 lo hondo

84 del principio: 
85 tú,

86 cordillera, tú, 87 crisálida

88 sonámbula

89 en el fulgor

90 impalpable

91 de tu corola:

92 tú,
93 nadie: tú.

94 Tú,

95 Poesía,

96 tú,

97 Espíritu,

98 nadie:

99 tú,

100 que soplas

101 al viento
102 estas vocales

103 oscuras,

104 estos

105 acordes

106 pausados

107 en el enigma

108 de lo terrestre:

109 tú:

\section{EI dolor de las cinco vocales (César Vallejo)}

\section{A Otilia}

1 Ves

2 lo

3 que

4 es

5 pues

6 yo

7 ya

8 no.

$9 \mathrm{La}$

10 cruz

$11 \mathrm{da}$

12 luz

$13 \sin$

14 fin.

Lima, mayo de 1919. 


\section{Vocales (A. Rimbaud)}

1 A negra, E blanca, Y roja, U verde, $\mathrm{O}$ azul: diré,

2 Vocales, algún día su virtual nacimiento.

3 Negro corsé velludo, la A, moscas brillantes,

4 Bombineando en torno a crueles hedores.

5 Golfos de sombra; E, candor de vapor y tiendas,

6 Lanzas de altos glaciar es, reyes blancos, umbelas;

7 Escalofríos. I, purpúreas, sangre escupida y risas

8 De hermosos labios en ira y embriagueces penitentes;

9 U, ciclos y vibramientos divinos de mares verdes,

10 Paz de pastos sembrados de animales, paz de arrugas

11 Grabadas por la alquimia en frentes estudiosas;

12 O supremo clarín de estridores extraños,

13 Silencios atravesados por Ángeles, por Mundos:

14 O la Omega, violeta el rayo de sus Ojos! 